\title{
Bibliotherapy: How Public Libraries can Support their Communities' Mental Health
}

\begin{abstract}
Bibliotherapy is the act of reading a book to aid a mental illness. Although bibliotherapy is commonly practiced in a controlled study, it should be expanded and implemented into public libraries in a way that the public can take bibliotherapy into their own hands. In this paper, bibliotherapy's effectiveness is looked at through both psychology tests and online public opinion. Also, its execution in public libraries is discussed, and better ways to implement bibliotherapy are suggested, based on literature on the topic. Overall, public libraries can take an active role in their community's mental health by providing them with tools in the form of books and resources to allow them to explore, understand, and potentially better their emotions or actions.
\end{abstract}

\begin{abstract}
About the Author: Keri MCCaffrey is a first year MLIS student at Dalhousie University. Her paper "Bibliotherapy: How Public Libraries can Support their Communities' Mental Health" was written for the course Information in Society. Because of her love of reading, Keri became interested in bibliotherapy and how books can affect a person's feelings and actions. She is interested in pursuing health science librarianship, which aligns with her interests in mental health and wellness.
\end{abstract}




\section{Introduction}

Reading books is often seen as a way to escape reality. It allows readers to immerse themselves in a different world and imagine themselves in multitudes of situations. For many people, it creates a safe place to explore new possibilities. Engulfing oneself in an alternate reality allows for the reader to become a part of the story, or one of the characters, feeling what those characters feel. Even in non-fiction, an authoritative voice can lead a reader through different emotions and realizations. This has the potential to be a very powerful aid for anyone willing to pick up a book, and potentially a therapeutic action taken on by the reader each time they choose to read for leisure.

Bibliotherapy is technically defined as prescribed readings to alleviate a mental illness ("Bibliotherapy", 2015). Bibliotherapy is commonly studied in psychology through focus groups. It relies on controlled aspects and, more often than not, prescribed non-fiction self-help books that were created by a psychologist. These specific studies are often narrowed down to a certain age group, or to a certain mental illness. The studies conclude by addressing whether bibliotherapy is potentially useful or not, and often imply that it needs to be further studied. However, personal testimonies of readers can show a powerful impact too, even though the results are not from a controlled environment. Bibliotherapy's self-help treatment applies not only to those diagnosed with mental illnesses, but to anyone that needs an emotional pick-me-up, an attitude change, or who needs help understanding and dealing with difficult issues.

Psychology's controlled bibliotherapy cannot completely show its full potential. Rather, public libraries should develop more in-depth booklists pertaining to specific and general mental health and wellness, create active displays, and keep an open conversation about mental health by using the aforementioned as framework for providing an alternative type of bibliotherapy. Ergo, this paper will begin by looking at the effectiveness of bibliotherapy through a literature review of controlledenvironment psychology studies. After this, it will look at first-hand accounts of bibliotherapy through online communities. Then it will assess public libraries' roles in bibliotherapy today, and how they can more actively support it in their respective role.

\section{Bibliotherapy through Psychology}

Before discussing the implementation of bibliotherapy in public libraries, it must be looked at more closely to understand its effect on people. Psychology studies provide a controlled way to get a sense of whether or not a practice works. Looking at the following studies, there are multiple examples of positive feedback from scholars 
suggesting that bibliotherapy is a good addition, or cheap alternative to clinical help. They look at all ages, ranging from children to adults, and cover mental illness and other mental issues. Looking at these will show the effect of bibliotherapy, and will validate if it is working in a controlled environment, and worth expanding or studying further to see if it can be effective in other contexts or environments.

It is well known that children benefit from reading. According to the American Academy of Pediatrics (2014), reading aloud to children from birth builds relationships between parents and children and is important in developing a child's language, literacy, and socio-economic abilities. Since reading is clearly beneficial to a child's development, it is possible that it could aid mental issues they have already developed. A study by Lewis, Amatya, Coffman, and Ollendick (2015) examined a group of nine children aged five to seven, who were categorized as having a fear of the dark. In this study, the children were read Uncle Lightfoot, Flip the Switch: Overcoming Fear of the Dark by their mothers. Uncle Lightfoot is a chapter book containing 19 chapters and a 28 page guide for the parents. The parent read this book to their child at least one to two hours per week over four weeks. After, all but one participant had a significantly lower feeling of anxiety towards being in the dark. On average, the results showed the children spent three extra nights per week sleeping in their own bed, which added three days to the initial average of two days per week. This increase in sleeping alone shows that the children benefitted from the study, and had significantly diminished fears. On top of this, there was a lowering in parent-reported separation anxiety. These results indicate that, in this controlled experiment, bibliotherapy, specifically Uncle Lightfoot, Flip the Switch: Overcoming Fear of the Dark, helped the children learn to cope with, or understand, their fear better (Lewis et al., 2015).

In "Bibliotherapy: An Indirect Approach to Treatment of Childhood Aggression" by Shechtman (1999), a group of ten eight-year-old boys were studied to see whether or not bibliotherapy could reduce their aggressive tendencies. The ten were chosen by their teacher (all from the same class) who identified six as highly aggressive, and added four others to fill the group, which was divided into two sections: control and experimental. The bibliotherapy was not self-directed, but rather was administered in 45 minute sessions to the group, involving various literature and other media. The sessions focused on issues that may cause aggression such as rejection or family issues. They found that the bibliotherapy helped reduce hostility in the aggressive boys. What was most interesting from this article was in their discussion: 
Literature seemed to have played an important part in facilitating these mechanisms of change, it presented the richness and complexity of life to the children, while stimulating curiosity yet minimizing defensiveness. Children could easily connect to their inner self through their identification with the characters in the literature, allowing them to understand the other's aggression as well as their own. Often, they used the titles of poems and stories as metaphors during the treatment process (e.g. "It isn't me, it's the monster," or "I am now my own commander"). However, the therapeutic discussion that followed helped in understanding the dynamics of aggression, and clearly enhanced the sense of being understood and accepted (Shechtman, 1999, p. 50).

This implies how books can help children relate to and understand difficult emotions and issues. These tactics combined with bibliotherapy could potentially be developed into children's programming in public libraries.

Teens often struggle with many issues from their childhood, growing up, and finding themselves. Many teens also enter fan communities of books and series that have clearly made a large impact on their life. Therefore, it is presumable that bibliotherapy could benefit teenagers and help them through their issues. In a specific study by Ackerson, Scogin, McKendree-Smith, and Lyman (1998), a group of 22 adolescents between grades six and twelve with mild to moderate depression participated in testing the use of psychology. The adolescents were asked to read Feeling Good by Burns - which was a revised version of a previous book also written specifically for this type of study - in a total of four weeks. Ackerson et al. found that bibliotherapy significantly helped the group who completed the book, even into the follow-up period. They suggested bibliotherapy is a good alternative to medication, and useful for children and teens (Ackerson et al., 1998). Even though this study focused on a mental illness, it is presumable that bibliotherapy could help with mental health and wellness in other ways too.

Alternatively, there are studies on bibliotherapy for parents to help their children. Forehand, Merchant, Long, and Garai (2010) completed a study involving parents of three to six year-olds. For this instance, the bibliotherapy was for the parents, but the end result was to see if the children's behaviour had changed from the parents' implementation of what the book had taught. The study asked for 52 parents that were looking to better their child's behaviour, and had two groups of parents read separate books: Parenting the Strong-Willed Child, and Touchpoints: Three and Six. Although both positively affected the behaviour of the children, Parenting the StrongWilled Child helped more (Forehand et al., 2010). This is yet another example of effective bibliotherapy where both books worked, however at different capacities. 
There are also examples of bibliotherapy in a general adult context through these controlled studies: first, Naylor et al. (2010) conducted a study on 19 participants aged 22-83. They were to read Feeling Good, by Burns. This group was then compared to another control group receiving typical treatment of the illness. Naylor and their team reported a significant impact on both the control group and the bibliotherapy group, including less undesirable attitudes, and an overall better quality of life was reported (Naylor et al., 2010). They deduced that bibliotherapy is at least as effective, if not more effective, on depression than regular care (Naylor et al., 2010). This is important because many studies had stated that bibliotherapy was a good addition to regular therapy, whereas Naylor et al. were providing the option of a completely self-directed care.

In another example, Malouff, Noble, Schutte, and Bhullar (2009) completed a study on bibliotherapy by looking to alleviate stress from participants experiencing tinnitus, a psychical issue causing high pitched noises in one's ear. It contained 162 people who were spilt into two groups: one sample participating in bibliotherapy, and another acting as a control group. Those assigned to bibliotherapy were sent the prescribed book by J. L. Henry and P. H. Wilson, Tinnitus: A Self-Management Guide for the Ringing in Your Ears. The participants were to read the entire book in two months. What was recorded was that bibliotherapy reduced the participants' problems by helping to relieve their stress, anxiety, and depression which were caused by the physical problem (Malouff et al., 2009). This is important because it lessened their physical issues by improving their mental health.

From these articles it is possible to see that bibliotherapy is very helpful in a controlled study with specific reading. The books were mostly, if not all, written by psychologists, and tended to be self-help non-fiction rather than focusing on a story, fiction or not. Their controlled studies indicate that bibliotherapy helps with common emotional problems, mental issues in any context, and parenting children. However, controlled environments and guided bibliotherapy is not always - or ever - possible for many people. This is interesting because the studies suggest that bibliotherapy is a good alternative for care because it is cheap and does not have time constraints. However, the studies imply that bibliotherapy is useful in a controlled context, much like clinical treatment. Therefore it is important to understand whether bibliotherapy helps in an out-of-clinical context. Since there cannot be any statistically sound studies conducted without it being controlled, determining whether or not bibliotherapy works in any other context must be done through experiences of librarians and readers. 


\section{Bibliotherapy in a Causal Context}

There are many forums on the Internet in which people can express their love for a book. Books often claim to draw the reader in entirely, or provide comfort. It is this idea of escapism, or being able to relate to a character with the same issues as you, that can allow a book to be therapeutic. Bibliotherapy in this context should be described as a way in which a book helps someone deal with an issue. In order to look at bibliotherapy in a non-clinical context to see whether or not books really help someone's mental health and wellness, social media will be used to look at specific opinions of users on how a book made them feel.

Buzzfeed, a common online website of popular media, has a "Buzzfeed Community" area where they ask their community, on their Facebook page and website, to comment on a particular question. Recently asked during their mental health week was "Which books have helped you manage your anxiety?" Here, people commented on the article, and on Facebook, saying which books curbed their anxiety, and sometimes why. Over 100 comments were made on this thread, and later an article - "23 Seriously Inspiring Books That'll Help You Manage Your Anxiety" (Kopsky, 2015) - was created highlighting a few. There were many popular books that were mentioned multiple times, and also a large breadth of what was read. Here are a few comments as highlights:

I read The Bell Jar after a really rough patch in my life. It comforted me more than anything else my family told me. While they mean well and I appreciate them, they have no knowledge of what it's really like to live with anxiety or depression. Reading Plath helped me better understand myself and gain perspective. (Leyva, 2015)

This quote shows that this particular book was more useful to that person than any verbal comfort from those close to them. The discerning factor was that the book made this person feel as though they were having the same experience as the main character. Likely, Leyva was able to see him or herself as the main character and was then able to share in the character's ups and downs, which let Leyva feel like he or she was not alone with his or her mental illness. Here is another comment:

Harry Potter. The fantastic, magical world that JK Rowling has created is the only thing that can calm me down when my anxiety goes haywire. I find it easier to lose myself in her world than deal with the issues in mine. (Lerner, 2015)

This statement is important because it clearly shows that Lerner was relying on escapism to ease his or her mental illness. Although escapism can seem to not be helpful by suppressing issues, it most likely would not be detrimental, especially for 
those with anxiety. This is because often those who suffer from anxiety just need a way to calm down and forget their irrational problems. Here is the next comment:

Girl with the Dragon Tattoo and Eleanor and Park. It made me realize that it's OK to be anxious - I'm not perfect and have flaws, but that doesn't mean I don't deserve to be happy or loved. (Greece, 2015)

This person was expressing that they came to terms with themselves through the aforementioned books. They helped this reader understand that no one is perfect, which allowed him or her to believe she was not alone and therefore gave him or herself permission and confidence to be happy. Lastly:

Grace's Guide: The art of Pretending to be a Grownup, by Grace Helbig. This book helped me recognise my anxiety and so felt confident enough to seek professional help (torib4b80f5754, 2015)

This quote is important because a book helped someone identify their issues, and encouraged them to get the help they needed. Also, this was one of the many nonfiction books which were not self-help oriented, but rather memoirs of a celebrity going through problems, or mental health issues similar to this reader. All of these quotes show the support these books have given readers, not only through a safe place to hide from the real world, but also in very life-changing ways.

Out of the Fog (2015) is a forum for those with personality disorders and for people dealing with those who have it. There were many threads related to books that help users with their issues. For example, a post by the user TalkingLeaves (2010) suggested a book for his or her peers to read called The Girl's Guide to Predators:

I was seeing him so clearly in there by about chapter three, I STRONGLY recommend this book for anyone grappling with anyone with NPD or ASPD, and wanting to be able to see clearly what they are, how they work, and how to avoid them in future.

Here the user is recommending a book for those who have been in a toxic relationship with someone who had a personality disorder. TalkingLeaves (2010) goes on to explain how the book acted as a medicine for them: "gosh it's good, and just the medicine for me at this point - like immunising myself before a potential access visit from him, and also immunising myself against making the same mistake again." A very relevant and notable comment in the thread came from user Karilty Belle (2010) who said "I hope more and more books like this start turning up on library/shop bookshelves." This is a strong point for the necessity of guiding these people to books that can help; to public library based bibliotherapy.

These examples from people online show that books can help in healing and guiding people outside of controlled environments. These are not only self-help books, which are still sometimes mentioned and used, but mostly fiction and relatable non-fiction. Compared to the clinical bibliotherapy - which focuses on a specific book helping in a controlled study - bibliotherapy in a public library setting would be much different, because librarians cannot conduct therapy. This, however, is not necessarily an issue 
against bringing bibliotherapy into public libraries. Rather, public libraries should find innovative and supportive ways to integrate bibliotherapy into their libraries.

\section{Bibliotherapy in Public Libraries}

In order to see why bibliotherapy should be integrated into public libraries more, it is necessary to look at public libraries' purposes and mandates. Generally, public libraries exist to serve the public. More specifically they are there to provide unbiased information, not only through books, but also through periodicals, computers, and local resources. They are there to support the community, more so than to exist as a storage area for information. Specifically, in the Canadian Library Association (CLA)'s Code of Ethics, members of the organization are to:

make every effort to promote and maintain the highest possible range and standards of library service to all segments of Canadian society; [and] facilitate access to any or all sources of information which may be of assistance to library users. (CLA, 1976)

These two points reflect the CLA's community focus. Bibliotherapy should be included in their ranges of services, and should be highlighted in public libraries to provide assistance to patrons. The second statement in particular emphasizes providing users with any information that will be useful to them, such as bibliotherapy. The American Library Association (ALA) says they will "increase recognition of and support for experimentation with innovative and transformative ideas" (ALA, 2015, p.5). This once again enforces the idea of embracing new services to provide to the public, which definitely encompass bibliotherapy. The International Federation of Library Associations and Institutions (IFLA) follows "the belief that people, communities and organizations need universal and equitable access to information, ideas and works of imagination for their social, educational, cultural, democratic and economic wellbeing" (2008, p. 2). This encompasses what bibliotherapy is there for, which is to help people with their mental well-being through the "ideas and works of imagination", such as books (IFLA, 2008, p. 2). Looking at these examples, it is easy to see that bibliotherapy fits well within the framework of a typical public library's policies, and should be implemented and continued so long as it is serving the community.

Bibliotherapy in a library setting can be pursued in a few different ways. In "The Power of Story: The Role of Bibliotherapy for the Library," Allen et al. (2012) highlight some very important points about bibliotherapy pertaining to libraries. When discussing the librarian's role in bibliotherapy, Allen et al. (2012) talk about libraries as being a safe sphere for children to learn and be themselves. They discuss that storytelling gives children role models and relatable scenarios (Allen et al., 2012). The characters depicted allow children to imagine themselves in those roles, which can allow them to 
learn and change in response to these stories (Allen et al., 2012). The effects on children in this instance are discussed relating to those who have experienced crisis, but many of these general statements can be applied to all children who presumably would be positively affected by bibliotherapy (Allen et al., 2012). Allen et al. (2012) also suggested a useful framework of addressing problem-solving with children. This article implies that librarians would be a very active part of bibliotherapy for children (Allen et al., 2012). Librarians could read a relevant book, and then engage the children with discussion in order to address their concerns and questions, and provide an informal, therapeutic, but most importantly, safe environment.

In Moulton's (2014) "Books that Help," she discusses her own way of implementing bibliotherapy in the library she works in. Moulton (2014) described overhearing a teen during one of her library programs expressing an issue of abuse she had previously dealt with. Understanding that the girl was in foster care and already had a support system for her problems, Moulton (2014) still wanted to aid the teen in some other way. A passive action taken by her was to create a display of books about mental health and to label them (Moulton, 2014). What she found was that by the next day, six of eight of the displayed titles were already taken out (Moulton, 2014). Also, Moulton (2014) had had previous experiences with those looking for mental disorder related books. In one case, the patron was very timid but was consistently asking for books about anxiety (Moulton, 2014). However, whenever she would take him to the nonfiction section, he would leave with nothing, and never gave any other indication of what he might want (Moulton, 2014). Fortunately, one day she was able to mention a fiction book on anxiety, and captured his attention, finally figuring out his need (Moulton, 2014). These examples are hinting at a need for bibliotherapy in public libraries delivered in many ways.

Bibliotherapy so far has been showing that books are therapeutic by escapism, by relating to characters, and by offering straight-forward help on various topics. With psychology, the books are specifically for self-help purposes, but a more modern take on bibliotherapy, such as seen in the online testaments and Moulton's (2014) article, is useful to mental health too. In Moulton's (2014) article, she searches to prove this, and asks the director of Adolescent Therapeutic Education and After School Services at Washington Count (VT) Mental Health Services. The director confirms that reading to children has been used to help them understand their own disabilities, and also to confirm that they are not the only ones going through an issue (Moulton, 2014). In a scenario like this, librarians can also help children understand others' experiences, such as disabilities (Moulton, 2014). This shows more support for bibliotherapy related to programming and involvement with children. 
In Husaini, Noordin, and Shuhidan's (2015) article on bibliotherapy applied to public libraries in Malaysia, they state that bibliotherapy is a way for librarians to help people through their "emotional, behavioral and social concerns" (p. 1). Today, librarians are less passive gatekeepers to information and more active educators and participators, which can be applied to bibliotherapy - especially with children. With the addition of programs, librarians could implement bibliotherapy to aid in sustaining and creating awareness of mental health, foreign concepts, and social issues (Husaini et al., 2015). Husaini et al. (2015) and other authors researching bibliotherapy focus on bibliotherapy for children, which seems to be combined with programming to teach about issues or problems. Since there are many studies on the benefits for reading to children, bibliotherapy is already very promising for children and is being implemented in public libraries. This can be seen through multiple bibliotherapy book lists specifically for children, or for parents to read to their children and discuss with them. For example, Vancouver Public Library (n.d.) has created a book list called "Bibliotherapy for counselling," which contains a few children's books on difficult topics. Also, Brooklyn Public Library (n.d.) has a book list called "Bibliotherapy," which contains solely children's books much like Vancouver's book list. Book lists are a good way to begin integrating bibliotherapy for children in public libraries, especially combined with programming. However, programs and promotion of bibliotherapy for teens and adults are also needed.

One way to have bibliotherapy in a public library for adults and teens is to have an inhouse bibliotherapist. In the UK, this seems to be more popular and possible. For example, East Ayrshire Library Services in Scotland has implemented a program called Read Yourself Well (MacDonald, Vallance \& McGrath, 2012). This allows for patrons to make an appointment with a bibliotherapist who will suggest books based on their mental health history (MacDonald et al., 2012). This program is also in conjunction with social services and health practitioners (MacDonald et al., 2012). However, the program focuses mainly on prescribing self-help books, and is more similar to the psychology side of bibliotherapy. MacDonald et al. (2012) felt that practicing this program through a bibliotherapist was a useful way of administering this in their public library. Although this is an option for practicing bibliotherapy in a public library, it is most likely not feasible for many libraries not only due to a lack of funds, but also due to an absence of bibliotherapists, who are less common in North America.

An initiative for bibliotherapy also exists in Ireland. Dublin Public Libraries helped sponsor a psychologist who, in conjunction with others, compiled a list of 30 effective self-help books (Dublin City Council, n.d.).This is a less hands-on approach, which seems to be common as seen in the children's lists before, and is perhaps not as useful 
as a one-on-one session. The fact that these two groups have limited their bibliotherapy to self-help books only is perhaps the worst detriment to their bibliotherapy programs. They should expand their initiatives and broaden the way to implement them.

\section{Issues and Recommendations}

Looking at some issues with bibliotherapy, the most obvious one is the need for a person to want to read. This was highlighted in some of the aforementioned studies, and is typical of any therapy. This clearly could have affected the previously mentioned psychology studies, and the bibliotherapy conducted in Scotland. However, the book lists and the display described in Moulton (2014)'s article are the two passive actions to implement bibliotherapy into the profession that do not pressure the patrons and their experience with the works. If using those two ways, combined with well-informed promotion of bibliotherapy, informed patrons could decide for themselves whether they would want to read a book to help with mental health.

What is important to remember is that librarians are not, in fact, mental health professionals. Although some public libraries can afford to have bibliotherapists, it is not necessary for all to follow this route. Rather, public libraries are there to provide information, as they always have. They could be there to promote books which have helped others, or that have been recommended by those with experience, and simply highlight any resources which may be helpful to their patrons.

If public libraries are going to implement bibliotherapy, they should focus on these two recommendations. First, developing comprehensive bibliotherapy lists - not focusing on non-fiction or fiction - including a variety of genres that can potentially help mental health and wellness. This is similar to what Moulton (2014) had in her article where she created a display of books on mental illness, where the books were almost completely checked out within 24 hours. This combines with the next recommendation, which is the promotion and advertising of the books. Displays and easy to find links to the book lists are necessary for bibliotherapy to be useful; after all, if no one can find the information, then it clearly cannot be used. Also, creating information on mental health and wellness with books could be informative and useful for patrons deciding whether or not they wish to partake in bibliotherapy. Likewise, creating programming with children and teenagers that addresses difficult issues and fosters learning in a safe environment is essential in administering to the younger population. 


\section{Conclusion}

In conclusion, bibliotherapy can be a very effective tool in aiding mental illness and helping maintain mental wellness. It can be administered not only through self-help books, but through any book that makes its reader feel less alone, or calmed and soothed by escaping into the story. Children can benefit from bibliotherapy by helping them learn new concepts and understand difficult issues. Psychology's take on bibliotherapy, or having a bibliotherapist in the library, is not necessarily the best way to introduce bibliotherapy to patrons or to implement a program. Rather, librarians should always strive to have the best information and programs for their patrons in order to support the community in as many ways as possible. 


\section{References}

Ackerson, J., Scogin, F., McKendree-Smith, N., \& Lyman, R. D. (1998). Cognitive bibliotherapy for mild and moderate adolescent depressive symptomatology. Journal of Consulting and Clinical Psychology, 66(4), 685690. doi: 10.1037/0022-006X.66.4.685

Allen, J. R., Allen, S. F., Latrobe, K. H., Brand, M., Pfefferbaum, B., Elledge, B., Burton, T., \& Guffey, M. (2012). The power of story. Children \& Libraries: The Journal of the Association for Library Service to Children, 10(1)

American Academy of Pediatrics. (2014). Literacy promotion: An essential component of primary care pediatric practice. Retrieved from http://pediatrics.aappublications.org/content/pediatrics/early/2014/06/19/p eds.2014-1384.full.pdf

American Library Association. (2015). Strategic plan: 2011-2015. Retrieved from http://www.ala.org/aboutala/sites/ala.org.aboutala/files/content/missionhist ory/plan/strategic\%20plan\%202015\%20documents/cd_36.2_2015_strateg.pdf

Bibliotherapy. (2015). In Merriam-Webster online. Retrieved from http://www.merriamwebster.com/dictionary/bibliotherapy

Brooklyn Public Library. (n.d.). Genre guide: Bibliotherapy. Retrieved from https://brooklyn.bibliocommons.com/list/show/199300025_teresaves3/199300 413_bibliotherapy

Canadian Library Association. (1976). Canadian Library Association code of ethics. Retrieved from http://www.cla.ca/AM/Template.cfm?Section=Position_Statements\&Templat $\mathrm{e}=/ \mathrm{CM} /$ ContentDisplay.cfm\&ContentID=3035

Dublin City Council. (n.d.). Bibliotherapy: The power of words. Retrieved from http://www.dublincity.ie/main-menu-services-recreation-culture-dublin-citypublic-libraries-and-archive-library-services 
Forehand, R. L., Merchant, M.J., Long, N., \& Garai, E. (2010). An examination of parenting the strong-willed child as bibliotherapy for parents. Behavior Modification, 34(1). 57-76. doi: 10.1177/0145445509356351

Greece. (2015). Which books have helped you manage your anxiety? [Discussion board posting]. In Buzzfeed Community. Message posted to http://www.buzzfeed.com/annakopsky/anxiety-books-addyours\#.ppoxVpDbv

Husaini, H., Noordin, S., \& Shuhidan, S. M. (2015). Bibliotherapy in context of public library: A conceptual framework. [Conference Paper]. Retrieved from https://www.researchgate.net/publication/278729015_Bibliotherapy_in_Cont ext_of_Public_Library_A_Conceptual_Framework

International Federation of Library Associations and Institutions. (2008). IFLA statutes. Retrieved from http://www.ifla.org/files/assets/hq/ifla-statutes-en.pdf

Karilty Belle. (2010). Topic: A really useful book - sums ASPD and NPD up. Out of the Fog. [Forum]. Message posted to http://outofthefog.net/forum/index.php?topic=3665.0

Kopsky, A. (2015, November 22). 23 Seriously Inspiring Books That'll Help You Manage Your Anxiety. Community on Buzzfeed. Retrieved from http://www.buzzfeed.com/annakopsky/anxiety-bookies\#.wrmoyyAj3

Lerner. (2015). Which books have helped you manage your anxiety? [Discussion board posting]. In Buzzfeed Community. Message posted to http://www.buzzfeed.com/annakopsky/anxiety-books-addyours\#.ppoxVpDbv

Lewis, K. M., Amatya, K., Coffman, M. F., \& Ollendick, T. H. (2015). Treating nighttime fears in young children with bibliotherapy: Evaluating anxiety symptoms and monitoring behavior change. Journal of Anxiety Disorders, 12(4). 103-112. doi: 10.1016/j.janxdis.2014.12.004

Leyva. (2015). Which books have helped you manage your anxiety? [Discussion board posting]. In Buzzfeed Community. Message posted to 
http://www.buzzfeed.com/annakopsky/anxiety-books-addyours\#.ppoxVpDbv

MacDonald, J., Vallance, D., \& McGrath, M. (2012). An evaluation of a collaborative bibliotherapy scheme delivered via a library service. Journal of Psychiatric and Mental Health Nursing, 20(10). 857-865. doi: $10.1111 /$ j.13652850.2012.01962.x

Malouff, J. M., Noble, W., Schutte, N. S., \& Bhullar, N. (2010). The effectiveness of bibliotherapy in alleviating tinnitus-related distress. Journal of Psychosomatic Research, 68(3). 245-251. doi: 10.1016/j.jpsychores.2009.07.023

Moulton, E. (2014). Books that help. School Library Journal. 60(11). 38.

Naylor, E. V., Antonuccio, D. O., Litt, M., Johnson, G. E., Spogen, D. R., Williams, R. McCarthy, C., Lu, M. M., Fiore, D. C., \& Higgins, D. L. (2010). Bibliotherapy as a treatment for depression in primary care. Journal of Clinical Psychology in Medical Settings, 17(3). 258-271 . doi: 10.1007/s10880-010-9207-2

Out of the Fog. (2015). [Forum] Retrieved from: http://www.outofthefog.net/forum/

Shechtman, Z. (1999). Bibliotherapy: An indirect approach to treatment of childhood aggression. Child Psychology and Human Development, 30 (1). 39-53. doi: 10.1023/A:1022671009144

TalkingLeaves. (2010). Topic: A really useful book - sums ASPD and NPD up. Out of the Fog. [Forum]. Message posted to http://outofthefog.net/forum/index.php?topic $=3665.0$

torib4b80f5754. (2015). Which books have helped you manage your anxiety? [Discussion board posting]. In Buzzfeed Community. Message posted to http://www.buzzfeed.com/annakopsky/anxiety-books-addyours\#.ppoxVpDbv

Vancouver Public Library. (n.d.). Genre guide: Bibliotherapy for counselling. Retrieved from https://vpl.bibliocommons.com/list/show/82089059_harry09/143843481_bibliot herapy_for_counselling 